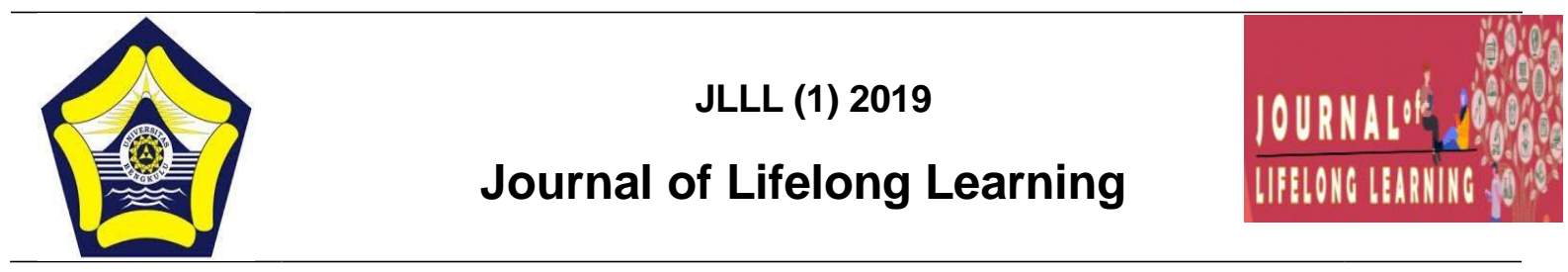

\title{
EFEKTIVITAS KEGIATAN KELOMPOK USAHA BERSAMA (KUBE) RAFFLESIA KABUPATEN BENGKULU UTARA
}

\author{
Devia Wanda ${ }^{1}$, Ilham ${ }^{2}$, Parlan ${ }^{3}$ \\ ${ }^{1}$ Nonformal Education, University of Bengkulu, Indonesia, deviaastika24@gmail.com \\ ${ }^{2}$ Nonformal Education, University of Bengkulu, Indonesia, ilhamadbullah418@gmail.com \\ ${ }^{3}$ Nonformal Education, University of Bengkulu, Indonesia, parlanunib@gmail.com
}

\section{Abstract}

General objective of this study was to determine the effectiveness of activities done by Rafflesia Business Group at the North Bengkulu. And the specific purpose of this study was to determine the planning, implementation, efforts to increase its capabilities to the members in the group, infrastructure, and the evaluation of Business Group program. The method of this study was a qualitative method and the data collection techniques used was interview, observation and documentation. The subjects of this research was Rafflesia Business Group board consisted of Chairman, Secretary, Treasurer and Members. In order to prove the validity of the research, it was checked by using the triangulation of data sources, techniques and timing. Data were analyzed through three stages, which were data reduction, presentation and conclusion. The research found that the first, Rafflesia Business Group did not use specific standards in planning the program it was only seen from the public interest, the planning was done with the consensus of the members. Second, implementation, Rafflesia Business Group implemented the program in accordance with the initial plan that had been prepared in advance with the cooperation of members to achieve production. Third, the efforts to increase the member participation in the group, members of the business made another attempt at Business Group. But they were always working to improve Business Group program in order to create new innovations. Fourth, influence of infrastructure, KUBE Rafflesia had sufficient infrastructure and assist in achieving the results of Business Group's program. Fifth evaluation, the evaluation was done associated with the planning done by the consensus of members, the implementation that was done matched with the advance planning in which the members were cooperated, the efforts to increased members participation in which they were always attempted to give new innovations for Business Group's program, and the infrastructure supported in achieving the results of Business Group.

Keywords: Effectiveness, Business Group, entrepreneurship 


\section{PENDAHULUAN}

Pendidikan Nonformal meliputi Pendidikan Kecakapan Hidup, Pendidikan Anak Usia Dini, Pendidikan Kepemudaan, Pendidikan Pemberdayaan Perempuan, Pendidikan Keaksaraan, Pendidikan Keterampilan dan Pelatihan Kerja. Pendidikan Kesetaraan meliputi Paket A, Paket B dan Paket $\mathrm{C}$, serta pendidikan lain yang ditujukan untuk mengembangkan kemampuan peserta didik seperti: Pusat Kegiatan Belajar Masyarakat (PKBM), Lembaga Kursus, Lembaga Pelatihan, Kelompok Belajar, Majelis Taklim, Sanggar, serta pendidikan lain yang ditujukan untuk mengembangkan kemampuan peserta didik.

Pendidikan Nonformal merupakan salah satu jenis layanan pendidikan yang bersifat kemasyarakatan seperti berbagai latihan keterampilan yang bermanfaat untuk mengaktualisasikan potensi manusia seperti sikap, tindak dan karya sehingga dapat terwujud manusia seutuhnya yang gemar belajar dan mampu meningkatkan taraf hidupnya. Pendidikan ini dilaksanakan salah satunya melalui satuan kelompok belajar yaitu Kelompok Usaha Bersama (KUBE). Program Kelompok Usaha Bersama (KUBE) merupakan salah satu solusi untuk mengurangi pengangguran di pedesaan, sebagai peningkatan kualitas sumberdaya manusia, serta menekan masalah sosial dengan mengoptimalkan potensi yang ada. Program KUBE perlu memperhitungkan pola kehidupan yang sedang berlangsung di masyarakat. Sesuai dengan tujuan KUBE, yaitu: (1) Peningkatan kemampuan berusaha para anggota KUBE secara bersama dalam kelompok, (2) Peningkatan pendapatan, (3) Pengembangan usaha, (4) Peningkatan kepedulian dan kesetiakawanan sosial diantara para anggota KUBE dan dengan masyarakat sekitar (Suryanto, 2010 : 01).

Program Kelompok Usaha Bersama (KUBE) merupakan gagasan yang dapat memberikan pemberdayaan bagi masyarakat kecil dengan meningkatkan kualitas hidup anggota. Anggota memiliki 3 arti, Anggota adalah sebuah homonym karena arti-artinya memiliki ejaan dan pelafalan yang sama tetapi maknanya berbeda, Anggota memiliki arti dalam kelas nominal atau kata benda sehingga anggota dapat menyatakan nama dari seseorang, tempat, atau semua benda dan segala yang dibedakan jadi anggota yang dimaksudkan adalah orang atau pelaku.

Berikut ini peneliti dapat merumuskan tujuan KUBE tersebut pada Kelompok Usaha Bersama (KUBE) pembuatan makanan ringan yang dilakukan oleh lembaga Kelompok Usaha Bersama (KUBE) Rafflesia yang ada di Desa Sumber Agung Kec. Arma Jaya Kab. Bengkulu Utara yang berdiri pada 06 Juli 1997 yang diketuai oleh Ibu Asetiamah dan telah memilki surat izin dari Dinas Pendidikan Kabupaten, keberhasilan usaha ini sudah pada tingkat provinsi dan merupakan binaan BKKBN Provinsi. salah satu lembaga yang peduli terhadap pendidikan masyarakat seperti melakukan kegiatan keterampilan yang sifatnya memberikan ilmu pengetahuan kepada masyarakat, lembaga sosial yang mempunyai fungsi membimbing dan membina masyarakat dengan harapan dapat memiliki usaha mandiri. Keseluruhan anggota yang tergabung di KUBE Rafflesia ini sebanyak 31 orang.

Adapun jenis-jenis produk olahan yang ada di KUBE Rafflesia ini diantaranya; (1) Baby fish crispy, (2) Keripik ubi ungu, (3) Keripik terong, (4) Keripik pare original dan pedas, (5) Keripik pisang, (6) Rangginang, (7) Minyak mahkota dewa, (8) Abon pisang, (9) Abon ikan, 
(10) Stik bayam, (11) Stik jagung, (12) Stik wortel, (13) Peyek kacang, (14) Kembang goyang, (15) Presta ubi, (16) Teh mahkota dewa, (17) Teh sirih merah (18) stik Rebung. Dari hasil pengamatan peneliti di KUBE Rafflesia Bengkulu Utara, alasan memunculkan permasalahan di Kelompok Usaha Bersama (KUBE) pembuatan makanan ringan yang dikelola oleh Kelompok Usaha Bersama (KUBE) Raflessia Bengkulu Utara ini antara lain kurang pahamnya masyarakat tentang apa itu Kelompok Usaha Bersama (KUBE), tidak ada kemauan untuk mengambil resiko, Perencanaan program yang tidak berubah, produk olahannya merupakan sayur-sayuran yang umumnya hanya diolah menjadi bahan makanan, kesibukan dalam mengurus rumah tangga dan mengurus sawah.

Berdasarkan permasalahan di atas maka peneliti tertarik untuk melihat bagaimana Efektivitas kegiatan KUBE terhadap kelompoknya. Oleh karena itu peneliti mengangkat penelitian ini dengan judul "Efektivitas Kegiatan Kelompok Usaha Bersama (KUBE) Rafflesia Kabupaten Bengkulu Utara".

\section{Metode}

Metode penelitian yang digunakan pada penelitian ini adalah metode kualitatif. Penelitian kualitatif adalah metode penelitian yang berlandaskan pada filsafat postpositivisme, digunakan untuk meneliti pada kondisi objek yang alamiah (sebagai lawannya eksperimen) dimana peneliti adalah sebagai instrument kunci, teknik pengumpulan data dilakukan secara triangulasi (gabungan), analisis dan bersifat induktif/kualitatif, dan hasil penelitian kualitatif lebih menekankan makna dari pada generalisasi (Sugiyono, 2006: 9). Hal tersebut sesuai dengan ciri dominan penelitian yang dikemukakan oleh Danim (2002:60-63) yaitu sebagai berikut: 1) sumber data langsung berupa tata situasi alami dan peneliti adalah instrumen kunci, 2) bersifat deskriptif, 3) lebih menekankan pada makna proses ketimbang hasil, 4) analisis data bersifat induktif, 5) makna merupakan perhatian utama dalam pendekatan penelitian.

\section{Hasil dan Pembahasan}

Ada perencanaan program pada KUBE Rafflesia yang tidak menggunakan standar khusus dalam menentukan perencanaan program karena hanya melihat peluang dan minat konsumen. Langkah-langkah pembuatan perencanaan program dengan musyawarah yang berakhir dengan mufakat anggota. Faktor pendukung dalam membuat perencanaan program adalah bahan baku dan manusia. Faktor penghambat dalam membuat perencanaan program ide dan inovasi baru. Perencanaan yang dimiiliki berbeda setiap tahunnya. KUBE Rafflesa tidak mempunyai perencanaan jangka pendek. KUBE Rafflesia juga melakukan pengamatan/pembaharuan pada segi rasa, ukuran dan inovasi lainnya. Perencanaan yang dimiliki KUBE sangat perlu dikembangkan seperti makanan ringan dan obat-obatan.

Pelaksanaan program KUBE Rafflesia selalu sesuai dengan perencanaan dan apa yang sudah disepakati dalam mufakat anggota. Setiap program yang ada di KUBE Rafflesia tidak selalu berjalan sesuai dengan perencanaan awal, Faktor pendukung dalam pelaksanaan program 
KUBE Rafflesia adalah tenaga kerja, peralatan, bahan baku, tempat, kemasan dan modal. Faktor penghambat dalam pelaksanaan program adalah bahan baku dan cuaca. Cara pengurus dalam mengatasi hambatan, mengganti dengan produk yang lain selain ikan dan produk yang tidak membutuhkan pengeringan sinar matahari langsung.

Upaya peningkatan kemampuan berusaha para anggota adalah usaha lain yang dimiliki seperti warung manisan, ketring, berjualan, kebun dan petani. Alasan mereka memilih usaha tersebut karena ingin membantu suami dalam hal pendapatan Penyebab usaha para anggota KUBE berbeda agar produk bervariasi dan menghindari perselisihan antar anggota, Usaha masing-masing anggota ditentukan dari KUBE. Sarana yang dimiliki KUBE Rafflesia cukup baik. Sarana yang dimiliki KUBE Rafflesia ada kompor, mesin pengiling tepung, mesin pengering minyak dan lainnya. Sarana yang dimiliki KUBE sangat dibutuhkan oleh anggota KUBE dalam membantu mereka memproduksi dan sarana tersebut sangat membantu kinerja anggota KUBE dalam pencapain hasil KUBE. Prasarana yang dimiliki KUBE Rafflesia juga cukup baik karena jalannya tidak ada yang rusak dan layak, kemudian gedung yang mereka gunakan sebagai sekretariat sangat baik karena layak untuk dalam pelaksanaan dan kegiatan KUBE, kebun milik KUBE tepat disamping sekretariat KUBE yang ditanami sayuran tanaman obat-obatan dan lainnya. Prasarana yang dimiliki KUBE sangat membantu kinerja dalam pencapaian hasil KUBE Rafflesia.

Evaluasi dilakukan KUBE Rafflesia pada perencanaan, pelaksanaan, upaya peningkatan, dan sarana prasarana. Perencanaan yang dimiliki KUBE tidak sesuai dengan perencanaan KUBE pada umumnya karena tidak menggunakan standar khusus. Perencanaan yang dimiliki KUBE merupakan faktor pendukung dari keberhasilan KUBE. Pelaksanaan yang telah dilakukan KUBE Rafflesia selalu mulus dan jarang mengalami kegagalan karena memang sudah sesuai dengan perencaan dan kerja sama yang baik. Pelaksanaan program, belum semua bisa dikatakan berhasil karena ada hambatan-hambatan yang tidak diprediksi sebelumnya. Pelaksanaan program KUBE terkadang sesuai dengan hasil yang dicapai dan ada juga yang tidak sesuai. Upaya yang dilakukan anggota KUBE sangat membantu dalam keberhasilan KUBE. Upaya dengan selalu membuat inovasi baru. Sarana dan prasarana sangat dibutuhkan oleh anggota KUBE. Maka dari itu sarana dan prasarana yang dimiliki KUBE Rafflesia sangat membantu dalam meningkatkan kinerja dan keberhasilan KUBE.

\section{Penutup}

Sesuai dengan permasalahan tujuan dan pembahasan, maka dapat disimpulkan bahwa

KUBE Rafflesia dalam mencapai efektivitas sudah bisa dikatakan berhasil. Ukuran yang memberikan seberapa jauh target dapat tercapai. Antara lain dilihat dari perencanaan sampai hasil yang dicapai. Dari hasil penelitian dilapangan tentang efektivitas kegiatan Kelompok Usaha Bersama (KUBE) Rafflesia Kabupaten Bengkulu Utara, bahwa:

1. Ada perencanaan program pada KUBE Rafflesia yang tidak menggunakan standar khusus dalam menentukan perencanaan program karena hanya melihat peluang dan minat konsumen. Langkah-langkah pembuatan perencanaan program dengan musyawarah yang 
berakhir dengan mufakat anggota. Faktor pendukung dalam membuat perencanaan program adalah bahan baku dan manusia. Faktor penghambat dalam membuat perencanaan program ide dan inovasi baru. Perencanaan yang dimiiliki berbeda setiap tahunnya. KUBE Rafflesa tidak mempunyai perencanaan jangka pendek. KUBE Rafflesia juga melakukan pengamatan/pembaharuan pada segi rasa, ukuran dan inovasi lainnya. Perencanaan yang dimiliki KUBE sangat perlu dikembangkan seperti makanan ringan dan obat-obatan.

2. Pelaksanaan program KUBE Rafflesia selalu sesuai dengan perencanaan dan apa yang sudah disepakati dalam mufakat anggota. Setiap program yang ada di KUBE Rafflesia tidak selalu berjalan sesuai dengan perencanaan awal, Faktor pendukung dalam pelaksanaan program KUBE Rafflesia adalah tenaga kerja, peralatan, bahan baku, tempat, kemasan dan modal. Faktor penghambat dalam pelaksanaan program adalah bahan baku dan cuaca. Cara pengurus dalam mengatasi hambatan, mengganti dengan produk yang lain selain ikan dan produk yang tidak membutuhkan pengeringan sinar matahari langsung.

3. Upaya peningkatan kemampuan berusaha para anggota adalah usaha lain yang dimiliki seperti warung manisan, ketring, berjualan, kebun dan petani. Alasan mereka memilih usaha tersebut karena ingin membantu suami dalam hal pendapatan Penyebab usaha para anggota KUBE berbeda agar produk bervariasi dan menghindari perselisihan antar anggota, Usaha masing-masing anggota ditentukan dari KUBE.

4. Sarana yang dimiliki KUBE Rafflesia cukup baik. Sarana yang dimiliki KUBE Rafflesia ada kompor, mesin pengiling tepung, mesin pengering minyak dan lainnya. Sarana yang dimiliki KUBE sangat dibutuhkan oleh anggota KUBE dalam membantu mereka memproduksi dan sarana tersebut sangat membantu kinerja anggota KUBE dalam pencapain hasil KUBE. Prasarana yang dimiliki KUBE Rafflesia juga cukup baik karena jalannya tidak ada yang rusak dan layak, kemudian gedung yang mereka gunakan sebagai sekretariat sangat baik karena layak untuk dalam pelaksanaan dan kegiatan KUBE, kebun milik KUBE tepat disamping sekretariat KUBE yang ditanami sayuran tanaman obat-obatan dan lainnya. Prasarana yang dimiliki KUBE sangat membantu kinerja dalam pencapaian hasil KUBE Rafflesia.

5. Evaluasi dilakukan KUBE Rafflesia pada perencanaan, pelaksanaan, upaya peningkatan, dan sarana prasarana. Perencanaan yang dimiliki KUBE tidak sesuai dengan perencanaan KUBE pada umumnya karena tidak menggunakan standar khusus. Perencanaan yang dimiliki KUBE merupakan faktor pendukung dari keberhasilan KUBE. Pelaksanaan yang telah dilakukan KUBE Rafflesia selalu mulus dan jarang mengalami kegagalan karena memang sudah sesuai dengan perencaan dan kerja sama yang baik. Pelaksanaan program, belum semua bisa dikatakan berhasil karena ada hambatan-hambatan yang tidak diprediksi sebelumnya. Pelaksanaan program KUBE terkadang sesuai dengan hasil yang dicapai dan ada juga yang tidak sesuai. Upaya yang dilakukan anggota KUBE sangat membantu dalam keberhasilan KUBE. Upaya dengan selalu membuat inovasi baru. Sarana dan prasarana sangat dibutuhkan oleh anggota KUBE. Maka dari itu sarana dan prasarana yang dimiliki KUBE Rafflesia sangat membantu dalam meningkatkan kinerja dan keberhasilan KUBE. 


\section{Refernsi}

Aditama Arikunto, Suharsimi. 2002. Metedologi Penelitian. Jakarta : Penerbit PT. Rineka Cipta.

Danim, Sudarwan. 2002.Menjadi Peneliti Kualitatif ; Pustaka Setia

Dinas Sosial Provinsi Yogyakarta. (2010). Kelompok Usaha Bersama (KUBE).

Suryanto. 2010. Kelompok Usaha Bersama. [Online]

Diaksesdarihttp://suryanto.blog.unair.ac.id/files/2010/01/kubepdf.pdf

Hikmat, Hari. 2010. Strategi Pemberdayaan Masyarakat. Bandung: Humaniora Utama Press.

J, Nasikun. 1995. Mencari Suatu Strategi Pembangunan Masyarakat Desa Berparadigma Ganda, dalam Jefta Leibo, Sosiologi Pedesaan. Yogyakarta: Andi Offset.

Makmur. 2011. Efektivitas Kebijakan Kelembagaan Pengawasan. Bandung: Refika (http: //digilib.unila.ac/7197/65/BABII.pdf (Diakses pada tanggal 10)

Mardikanto, Totok. Dkk. 20013. Pemberdayaan Masyarakat Dalam Perspektif Kebijakan Public.Bandung: Alfabetta Cv.

Moleong, Lexy J. 2005. Metodologi Penelitian Kulaitatif. Bandung: Remaja Rosda karya. Visiunivesal. 2015. Konsep Program pendidikan kecakapan. [Online]

Diaksesdarihttps://visiuniversal.blogspot.co.id/2015/01/konsep-program-pendidikankecakapan.html

Peraturan pemerintah NO.73 Tahun 1991 Tentang Pendidikan Luar Sekolah. http://bpbayupradikto.blogspot.co.id/2014/01/ketwrkaitan-antara-pendidikan-nonformal.html (Diakses pada tanggal 18 Oktober 2017)

Siagian, P. 2005. Fungsi-Fungsi Manajerial. Jakarta: Bumi Aksara

Sudjana. 2008. Evaluasi Program PLS. Bandung. PT Remaja Rosdakarya Offset

Sugiyono. 2006. Metode Penelitian Kuantitatid Kualitatif dan R\&D. Bandung: Alfabeta,Cv.

Sumarsono, Sonny. 2013. Kewirausahaan. Yogyakarta: Graha ilmu. GhafarArifRM.Abd. 2013. Prakarya Dan Kewirausahaan. [Online]

Diaksesdarihttp://Abd.GhafarArifRM.blogspot.co.id/2013/12/prakarya-dan-kewirausahaan.html

Terry, George. 1986. Asas-Asas Manajemen. Bandung: Penerbit Alumni

Undang-Undang RI No. 20 Tahun 2003. Tentang Sistem Pendidikan Nasional. Jakarta : Cemerlang 